\title{
Comparative Analysis of Heat Transfer and Friction Characteristics in a Corrugated Tube
}

\author{
Shahuraj Karape*, M. S. Deshmukh and A. A. Pawar \\ ${ }^{\dagger}$ Department of Mechaniacal Engineering,S.P.University,Pune,R.S.C.O.E Pune,Maharashtra,India-411033
}

Accepted 15 June 2016, Available online 20 June 2016, Special Issue-5 (June 2016)

\begin{abstract}
An experimental study of heat transfer in plane circular tube and corrugated tube is performed. The objective of this Project work is to analyses heat transfer coefficient and friction factor characteristics in a circular corrugated tube and compare the result with CFD analysis. The experimentation was firstly carried out for plain circular tube and then for corrugated tube and heat transfer augmentation was recorded. Both these results are compared. All experiments were carried out at the different mass flow rate. In this paper plain circular pipe with $42 \mathrm{~mm}$ outer diameter and $34 \mathrm{~mm}$ inner diameter was taken. And corrugated pipe was manufactured by doing internal threading of $6 \mathrm{~mm}$ pitch and $3 \mathrm{~mm}$ depth with $60^{\circ}$ threading angle. For both readings air is taken as working fluid. At the Reynolds number range of 1000-6100, internal threaded corrugated tube were examined and the result are compared to the plain tube. Result shows that heat transfer enhancement of 1.13-1.19 have been achieved and friction factor range from 0.6 to 1.2 .
\end{abstract}

Keywords: Internally threaded corrugated pipe, heat transfer coefficient, pressure drop.

\section{Introduction}

In previous years, many researchers have done on methods for heat transfer enhancement in heat exchangers and thermal energy transport devices. These methods received great attention in order to fulfill for the growing needs of higher efficiencies in these devices. There are mainly two basic techniques used to increase the rate of heat transfer. One is passive method and other is active method. The passive method requires certain surface geometries or fluid additives and active method requires certain external sources.

The main aim of this activity is to obtain a more efficient heat exchangers and thermal energy transport devices for many other industrial applications with the main goal being to provide energy, material and economic saving for users of heat transfer enhancement technology. Corrugated tube is widely utilized in various heat exchangers to enhance heat transfer performance by intermittently destroying the momentum and thermal boundary layers on the inner and outer walls of it. Corrugated surface geometry is one of the many suitable passive techniques to enhance the heat transfer in thermal energy transfer devices.

Why Corrugated Tubes Developed?

1. To increase the tube side heat transfer coefficient with minimum increase in pressure loss.
2. To overcome disadvantages of other methods of artificial enhancing the heat transfer coefficient, viz.,

- Increased resistance to fluid flow- increased pressure loss.

- Difficult to design / manufacture / replace / service

- Difficult to clean

- Low running reliability

3. To have efficient heat transfer even in liquids with high viscosity, liquids with large fibers or particulates.

Therefore, an increase in the efficiency of the heat exchanger through this technique may result in a considerable saving in the material cost. Furthermore, as a heat exchanger becomes older, the resistance to heat transfer increases owing to fouling or scaling. These problems are more common for heat exchangers used in marine applications and in chemical industries. In some specific applications, such as heat exchangers dealing with fluids of low thermal conductivity (gases and oils) and desalination plants, there is a need to increase the heat transfer rate. The heat transfer rate can be improved in this technique by introducing a disturbance in the fluid flow (breaking the viscous and thermal boundary layers), but in the process pumping power may increase significantly and ultimately the pumping cost becomes high. 


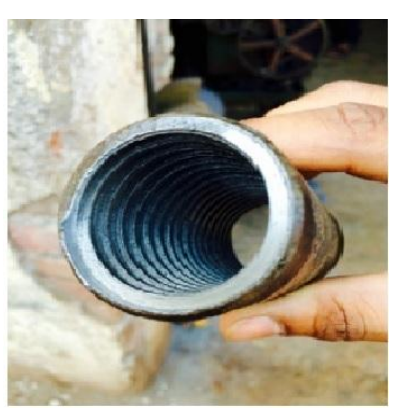

Fig.1 Image of the corrugated pipe

\section{Literature Review about corrugated pipe}

M.N.Nazr: In his study, three different spiral corrugation profiles have been examined to determine which geometry has the best heat transfer enhancement these are circular, waved and curved corrugation profile. The curved corrugation tube has the best thermal performance among the other corrugation types. While the circular corrugation tube has the lowest heat transfer enhancement and the waved corrugation tube is in between. They have enhancement of (18.4-36.3) \% for $\mathrm{Re}=100-1300$ as compared with smooth pipe. In this paper computational fluid Dynamics simulation of heat transfer and fluid flow analysis in laminar flow regime in spirally corrugated tubes with horizontal orientation are presented. Constant wall heat flux condition was applied with water as a working fluid. From this paper we conclude that, for constant heat flux condition with water as working fluid and at laminar condition, it was found that whole three geometries have poor heat transfer performance at low Re and good at high Re.

M. Faizal: In this paper he studied the heat transfer and pressure drops in a corrugated plate heat exchanger with variable spacing and variable warm water flow rates were studied with help of temperature measurements at the inlet and exit of the plate heat exchanger. It is found that for a given plate spacing with increasing hot water flow rate, the average heat transfer between the two streams increases due to high turbulence at higher velocities. From this paper we conclude that for wavy corrugation plates with water as a working fluid, the average heat transfer between the two streams increases due to high turbulence at higher velocities.

S. V. Karmare: In this paper he presents an experimental investigation of heat transfer performance of a rectangular duct with metal grid ribs as roughness element employed on one broad wall, transferring heat to the air flowing through it. The wall is subjected to uniform heat flux. The effect of relative length, height and pitch of the metal grid ribs on the heat transfer and friction factor studied for the flow range of Reynolds number 4000-17000. From this paper we conclude that for rectangular duct with constant heat flux and water as working fluid for turbulent flow, heat transfer enhancement was increases with increase in Reynolds number.
Yong Dong: In this paper experimentally carried out the rate of heat transfer with spirally corrugated tubes and varies geometrical parameters with considering that the water and oil is working fluid. By using different Reynolds number with the separate range of water is 6000 to 93000 and range for oil is 3200 to 19000. They are carried out the experiment and for that some important assumptions are made like, both enhanced tube and smooth tube exchanger having equal entering pressure, Tube side fouling resistance and wall resistance neglected. The enhanced tubes showed an enhancement in tube side heat transfer coefficient ranging from $30 \%$ to $120 \%$ and friction factor enhancement of $60 \%$ to $160 \%$ when compared to smooth tubes. From this paper we conclude that, for water as a working fluid and inward spirally corrugated tube with turbulent flow it is found that thermal performance of these tubes were superior compared to smooth tube.

Wen Tao ji: In this study a comprehensive literature survey on the thermal hydraulic performance of liquid flow and heat transfer in pipe with internal fins, twisted tape insert, corrugation, dimples, and compound enhancement technique is conducted. It found that for turbulent heat transfer the enhancement ratio of experimental Nusselt number over DittusBoelter equation for corrugated tube is $1.5-4$. The ratio of friction experimental friction factor over Fanning equation is mostly in the range of 2-6 for corrugated pipe. From this paper we conclude that, for water an oil as a working fluid with inward spirally corrugated tube, the heat transfer enhancement ratio are larger than the increment in pressure drop penalties.

M.A. Ahmad: In this paper heat transfer enhancement an pressure drop due to flow of copperwater nano fluid through isothermally heated corrugated are studied numerically for range of Reynolds number of 100-1000 and nanoparticle volume fraction varying from 0 to 0.05 . For $\operatorname{Re}<200$, there is slight increase in the enhancement with increase in Reynolds number, while for Re $>200$, there is slight decrease in the enhancement as Reynolds number increases. They found that, the highest heat transfer enhancement was found at Reynolds number of 200 and nanoparticle volume fraction of $5 \%$, with enhancement of around $43.9 \%$ over the base fluid. From this paper we find that, for isothermally heated condition with copper water nanofluid, it was found that at low $\mathrm{Re}$ there was slight increase in enhancement with increasing in Re. While for the high Re there was slight decrease in heat transfer enhancement as Reynolds number increases. Thus this study shows that the use of nanofluid in corrugated channel can be proposed as a suitable method to achive higher heat transfer performance.

Huai-Zhi Han: In this paper, the flow and heat transfer characteristics in convex corrugated tube have investigated through numerical simulation. They studied two types of corrugated tube named as symmetric corrugated tube and asymmetric 
corrugated tube and are modeled and studied numerically based on $\mathrm{k}-\varepsilon$ model. Numerical simulation results for flow and heat transfer performance in symmetric corrugated tube and asymmetric corrugated tube with various geometrical parameters, including corrugated pitch, corrugation height and corrugation trough radii are systematically analyzed. Compared to the symmetric corrugated tube, asymmetric corrugated tube exhibits 8-18\% higher overall heat transfer performance. From this paper we conclude that for outward convex corrugated pipe with water as a working fluid, it is found that thermal performance of the tube is high as compared with smooth pipe at high Reynolds number.

But in this paper we conducted the experimental study on internally threaded corrugated pipe with air as working fluid.

Thus corrugated tube is produced by indenting a plain tube with a spiral pattern. It is very difficult to manufacture the corrugated pipe with the internal threading for such a long pipe. So we cut this long pipe into small pieces then internal threading is done. And these small pieces are joined by welding after that this long pipe is finished by turning. For matching the threads we use the tool the external threading as shown in figure 1 . This imparts different flow regimes - spiral in the core and eddy's at the periphery. The helical flow contributes to the situation that the fluid particles are alternatively in the vicinity of the tube and then in the main flow. Between the helical impression, around the circumference of the tube, secondary flow, typically in the form of eddies occur. Increasing in heat transfer coefficient brings the temperature of the tube wall closer to the temperature of the bulk fluid on the tube.

\section{Experimental Setup}

The experiment will carried out in open loop experimental facility as shown in figure. The loop consists of blower, an anemometer to measure the flow rate, thermocouple to measure the temperature. The pressure drop of the heat transfer test section is measured with pressure gauge. The volumetric air flow rates from the blower are adjusted by varying motor speed through the inverter, situated before the inlet of test tube.

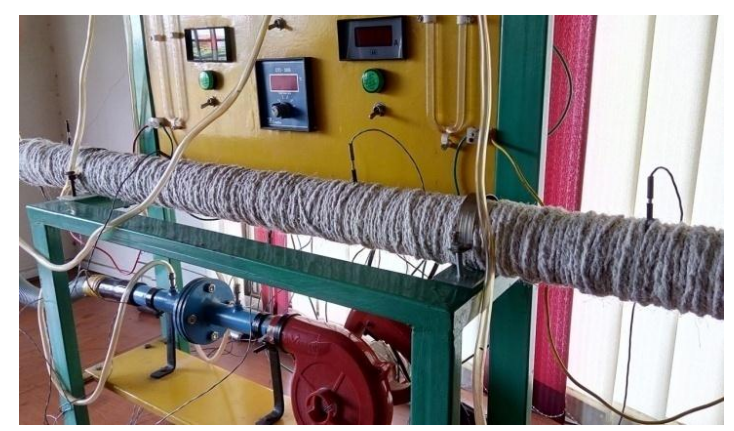

Fig. 2 Experimental setup
During the experiment, the bulk of air is heated by an adjustable electrical heater wrapping along the test section. Both the inlet and outlet temperature of the bulk air from the tube are measured by thermocouple. The temperature will be measured at the 8 stations altogether on the outer surface of the transfer test pipe for finding out average Nusselt number. The various characteristics of the flow, the Nusselt number, and the Reynolds number are based on the average of tube wall temperature and outlet air temperature. The local wall temperature, inlet and outlet air temperature, the pressure drop across the test section and flow velocity are measured for the heated plain tube and then for corrugated tube. The average Nusselt number are calculated and all fluid properties are determined at the overall bulk temperature. The experiment is conducted and analysis is done.

\section{Experimental step wise procedure}

In the present work, the air is used as working fluid and flowed through an uniform heat flux and insulation tube. The steady state heat transfer rate is assumed to be equal to the heat loss from the test section which can be expressed as:

$Q_{\text {air }}=Q_{\text {conv }}$

Where,

$\mathrm{Q}_{\text {air }}=\mathrm{mC}_{\mathrm{pa}}\left(\mathrm{T}_{\mathrm{o}}-\mathrm{T}_{\mathrm{i}}\right)$

$\mathrm{Q}_{\text {conv }}=\mathrm{hA}\left(\mathrm{T}_{\mathrm{w}}-\mathrm{T}_{\mathrm{b}}\right)$

1. First calculate the mass flow rate in $\mathrm{Kg} / \mathrm{sec}$ using the following equation $\mathrm{m}=\rho \mathrm{AV}$

2. Then calculate the Reynolds number by using, $\mathrm{Re}=$ $\frac{\rho V d}{\mu}$

For flow through the pipe

a) Laminar flow $(\operatorname{Re}<2000)$

$\mathrm{Nu}=4.36 \quad$ (For constant heat flux)

$\mathrm{Nu}=3.66$ (For constant wall temperature)

b) Turbulent flow $(\operatorname{Re}>4000)$

Dittus-Boelter equation

$\mathrm{Nu}=0.023 \mathrm{Re}^{0.8} \operatorname{Pr}^{0.4}$ (Fluid is heated)

$\mathrm{Nu}=0.023 \mathrm{Re}^{0.8} \mathrm{Pr}^{0.3} \quad$ (Fluid is cooled)

3. Then calculate heat transfer coefficient from the equation given below,

$N u=\frac{h d}{k}$

4. Then calculate the convection heat transfer from the test section,

$\mathrm{Q}_{\text {conv }}=\mathrm{hA}\left(\mathrm{T}_{\mathrm{w}}-\mathrm{T}_{\mathrm{b}}\right)$

Where, 
$\mathrm{T}_{\mathrm{w}}=\frac{\sum T_{w}}{6}$

$\mathrm{T}_{\mathrm{b}}=\frac{T_{o}+T_{i}}{2}$

$\mathrm{T}_{\mathrm{o}}=$ Outlet temperature of air.

$\mathrm{T}_{\mathrm{i}}=$ Inlet temperature of air.

5. Finally calculate the Friction Factor by using,

$$
\mathrm{f}=\frac{\Delta P}{\left(\frac{L}{d}\right)\left(\rho \frac{V^{2}}{2}\right)}
$$

\section{Software Analysis}

The commercial package of CFD (ANASY-16.0) was chosen as the CFD tool for this study to solve the above mentioned governing equation accompanied with boundary conditions. Solution sequential algorithm with settings including implicit formulation, steady calculation, viscous laminar model and energy equation, simple as pressure velocity method, and first order upwind scheme for energy and momentum equation was selected for simulation.

\section{Opening/Creating a project}

All the files required for a particular analysis are contained within a project. Here we have created a new project.

\section{Creating /Manipulating the Geometry}

The ANSYS ICEM environment has combined CAD surface geometry and triangulated surface data into a single geometry database using the geometry interface. All geometry entities, including surface, curves and points are tagged or associated to a grouping called parts. With this part association, we did enable or disable all entities within the parts, visualized them with a different colour, assigned mesh size on all entities within the part and applied different boundary condition by part.

\section{Creating the Tetramesh}

The ANSYS ICEM CFD tetra mesh is a semi-automated meshing module which allows rapid generation of multi-block structured hexahedral volume meshes.

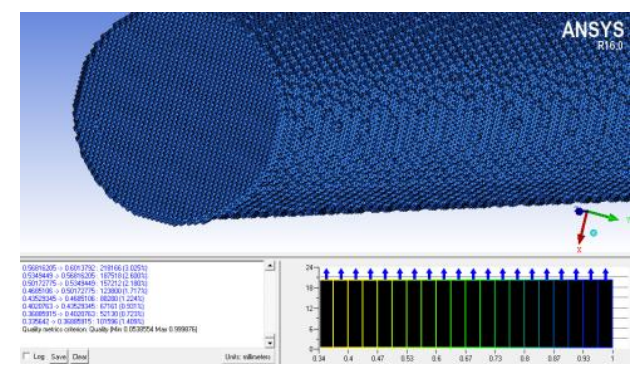

Fig.3 Meshing for Corrugated Pipe

ANSYS ICEM Tetra represents a new approach to grid generation where the operation most often performed by experts are automated and made available at the touch of button. Block can be built and interactively adjusted to the underlying CAD geometry. The mesh count is 6.4 million and mesh quality is 0.34 .

\section{Generating the Input for solver}

ANSYS ICEM CFD includes output interface to various flow and structural solvers, producing appropriately formatted files that contain complete mesh and boundary condition information. After selecting the solver, we modified the solver parameter and write the necessary input files.

\section{Post processing}

ANSYS fluent CFD allowed viewing the solution results from different solvers. The results file must be loaded to make the post processing menu active. Here we visualized results using calculate integral, graphics and animation and plot XY files.

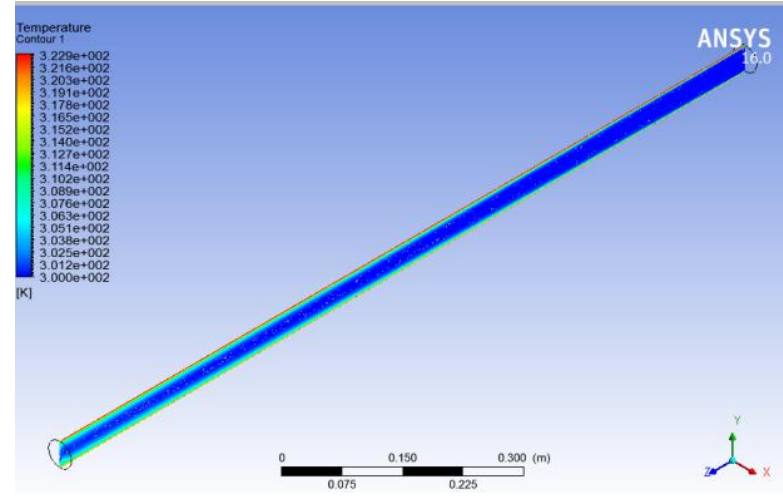

Fig.4 Temperature variation for simple pipe

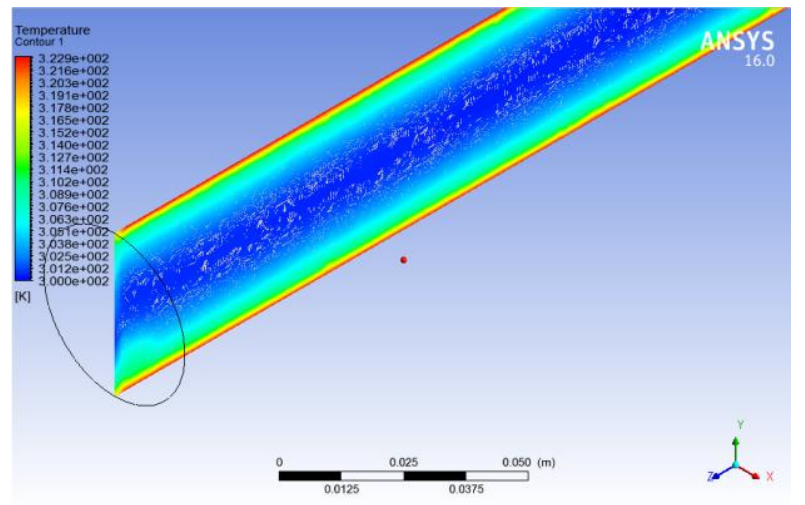

Fig.5 Temperature variation at inlet along the diameter for simple pipe

\section{Result and Discussion}

The number of readings were taken for different air velocity for plane circular pipe and then for corrugated pipe. Finally experimental results were compared with CFD analysis by using ANSYS - 16.0 software tools.

1) Nusselt number vs. Reynolds number 


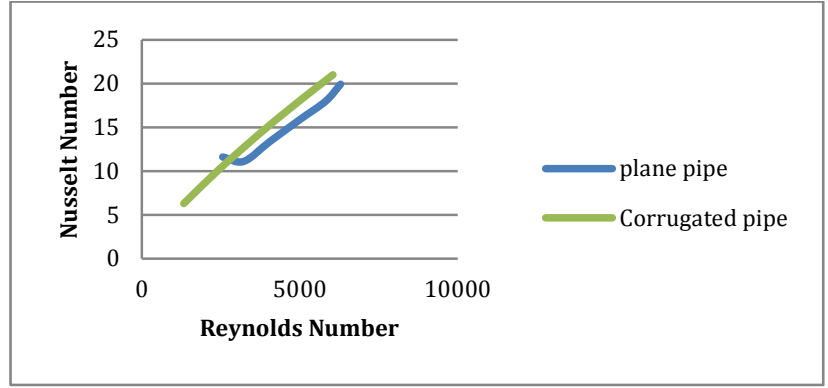

Fig. 6 Nusselt number vs. Reynolds number

The heat transfer coefficient is mainly calculated from Nusselt number. As Nusselt number increases heat transfer coefficient also increases. Figure shows that as Reynolds number increases Nusselt number also increases as a result heat transfer coefficient increases. Nusselt number obtained for corrugated tube is slightly higher than plain tube. This increase in Nusselt number clearly indicates that heat transfer rate is increased by using corrugated pipe.

2) Heat transfer coefficient vs. Reynolds number

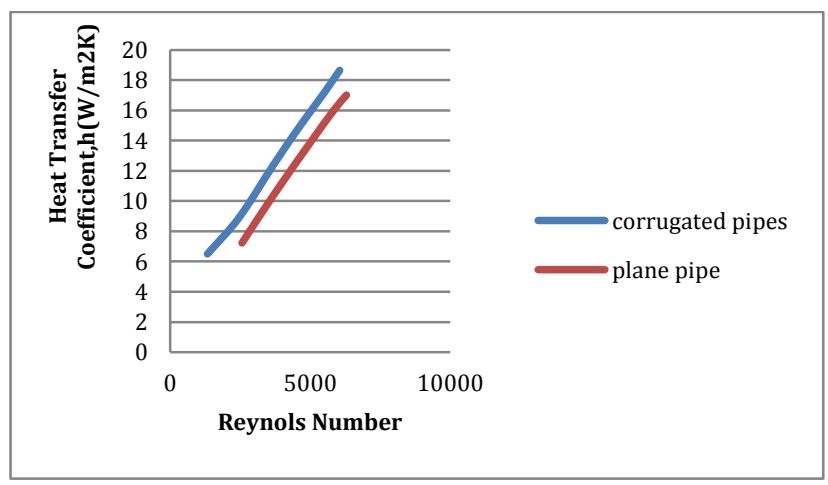

Fig. 7 Heat transfer coefficient vs. Reynolds number

As Nusselt number increase heat transfer coefficient also increases. From figure it can be seen that as Reynolds number increases heat transfer coefficient is also increases in turn increases heat transfer rate. Figure shows that the increase in heat transfer coefficient for corrugated pipe is greater than plane pipe.

3) Friction factor vs. Reynolds number

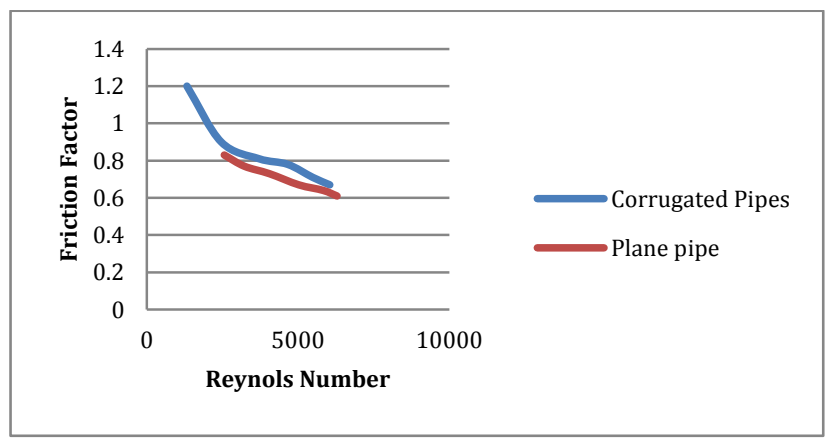

Fig. 8 Friction factor vs. Reynolds number
It is very important to determine friction factor for an heat exchangers, because increases in friction factor increases the losses and increases the input power required in turn reduces life of the component. The graph shows variation of friction factor vs. Reynolds number for both plain pipe and corrugated pipe. The friction factor reduces with increase in Reynolds number.

\section{4) CFD results vs. Experimental results}

The experimental results are compared with numerical result by varying mass flow rate of the air.

As experimental results, as shown in figure by varying mass flow rate, there is raising and falling the flow of fluid due to blower air which fluctuates the pressure across the wall due to which pressure gets negligible rise or remains constant. While in numerical results, pressure consecutively increased because of smooth flow of fluid.

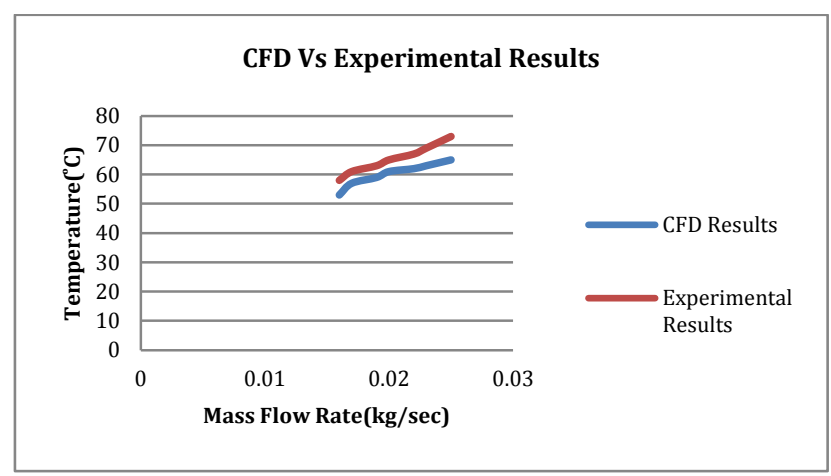

Fig. 9 Temperature vs. Mass flow rate

In the experimental results as shown in figure by varying the mass flow rate, due to surface roughness at the wall due to corrugation more fluid particles are mixed with each other and created turbulence which make rise in temperature. In numerical results, due to smooth distribution of air, temperature is uniform.

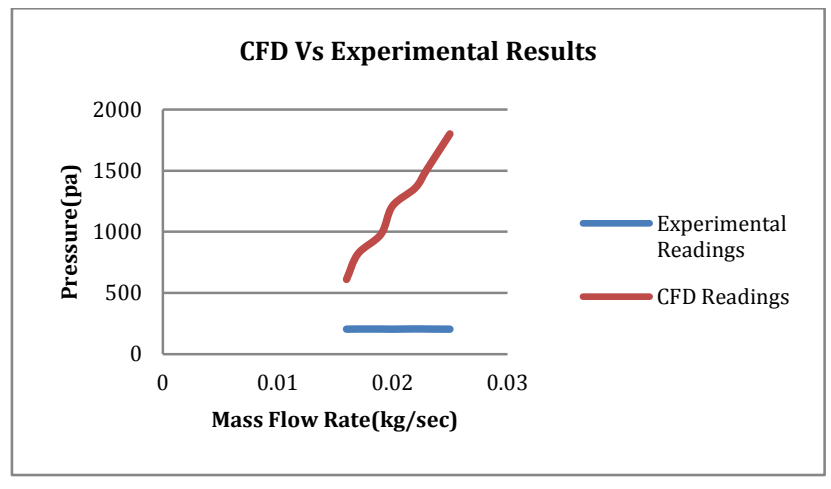

Fig. 10 Pressure vs. Mass flow rate 


\section{Conclusion}

Experimental investigation and CFD analysis have been carried out to study the effect corrugated pipe on heat transfer coefficient, friction factor and enhancement efficiency as compared with circular pipe. The plain pipe having outer diameter $42 \mathrm{~mm}$ and inner diameter $34 \mathrm{~mm}$. The corrugated pipe having outer diameter $42 \mathrm{~mm}$ and inner diameter $34 \mathrm{~mm}$ but it is manufactured with internal threading of pitch $6 \mathrm{~mm}$ and depth $3 \mathrm{~mm}$. Using air as working fluid reading were taken and following conclusion were drawn.

1) As Reynolds number increases the heat transfer coefficient also increases. Increasing in heat transfer coefficient is higher for corrugated tube. For Reynolds number ranger of $1000-6100$, it is found that heat transfer enhancement of 1.13-1.19 have been achieved at different velocities of air.

2) The friction factor reduces with increasing in Reynolds number. Pressure drop was slightly higher for corrugated pipe. Friction factor range from 0.6 to 1.2 for corrugated pipe.

3) As Reynolds number increases Nusselt number also increases. Increasing in Nusselt number is higher for corrugated pipe

\section{References}

M.N.Nazri, TholudinM.Lazim "Corrugation profile effect of heat transfer enhancement of laminar flow region", International conference on Mechanical and industrial engineering, Feb 8-9 2015.

M.Faizal "Experimental studies on a corrugated plat heat exchanger for small temperature difference application"Vol.36, (2012) pp.242-248.

S.V.karmare,"Heat transfer and friction factor correlation for artificially roughened duct with metal grit ribs"ScienceDirect, Heat and mass transfer

Yang Dong "pressure drop, heat transfer and performance of single phase turbulent floe in spirally corrugated tubes" Elsevier, Vol 24(2001)pp.131-138.

Wen-Tao Ji "Summery and evaluation on single phase heat transfer enhancement techniques of liquid laminar and turbulent pipe flow" Science Direct, Vol 88(2015) pp. 735754.

M.A. Ahmad "Effect of geometrical parameters on flow and heat transfer characteristics in trapezoidal-corrugated channel using nanofluid" Science Direct, Vol 42 (2013) pp. 69-74.

Huai-Zhi Han, Bing-Xi Li "Numerical study of flow and heat transfer characteristic in outward convex corrugated tubes." Science-Direct, International Journal Heat and mass transfer Vol. 55 (2012) 7782-7802. 